\title{
Knowledge Management Framework for Cloud Federation
}

\author{
Wahiba Mellaoui ${ }^{(凶)}$, Richard Posso, Yodit Gebrealif, Erik Bock, Jörn Altmann ${ }^{(凶)}$, \\ and Hyenyoung Yoon
}
Technology Management, Economics and Policy Program, College of Engineering, Seoul National University, Seoul, South Korea
jorn.altmann@acm.org, hyyoonoo@snu.ac.kr

\begin{abstract}
A cloud federation (CF) is an alliance of cloud service providers (CSPs) working together to overcome scalability and portability barriers. However, there are some business challenges (e.g., lack of trust, lack of schemes for revenue sharing, and lack of schemes for resource sharing) and technological challenges (e.g., missing schemes for resource provisioning, lack of coordinated resource management, and little load balancing), causing instability in CFs. As CF alliances pursue strategic goals, they require intensive knowledge sharing. In fact, practitioners have confirmed a positive impact of knowledge management on stability and success of strategic alliances (SA). According to the literature, SAs may also face learning issues such as non-controlled information revelation or unbalanced dissemination of core competencies. These findings pose challenges about the nature of the knowledge and how to share it within a CF. Nonetheless, there is only scarce literature on KM in CF. Thus, the purpose of the paper is to propose a KM framework for CFs with the aim of strengthening stability and potential $\mathrm{CF}$ commercialization.
\end{abstract}

Keywords: Cloud federation · Knowledge management - Strategic alliance

\section{Introduction}

In cloud federations (CFs), various cloud service providers (CSPs) are collaborating, when it comes to delivering services. However, there are issues and challenges that hamper the commercialization of CFs; lack of trust between CSPs is considered one of the reasons hindering CFs [1]. Although trust among CSPs is the basic element for commercializing CFs, trust-building technologies have not been seen in market yet [2]. Trust between CSPs could be created in several ways. One solution is providing an accountable and measurable platform, in order to share CSPs information and knowledge among the CSPs in a CF [3].

Scholars have not explored the relation between knowledge management (KM) and CF sufficiently. Only few articles discussed about KM relation with CF such as $[4,5]$. This led to the exploration of the relation between KM and SA instead of KM and CF. From the research on this relation, evidence was gained of a strong relation between KM 
and stability of a SA [6-8]. Based on this newly discovered information, a search was started for a model that explains the relation between KM and SA stability with trust as the main enabler of knowledge sharing. The search resulted in the adoption of the model of inter-organizational system collaboration [9]. Furthermore, it was enhanced by detailing the KM components.

The goal of this paper is to provide insight into how KM helps CFs come closer to being commercialized [14]. Thus, the following research questions were elaborated:

- What are the requirements of applying $\mathrm{KM}$ to $\mathrm{CF}$ ?

- How should a framework on KM for CF be defined?

- What is the impact of KM on the stability of CF as a SA?

To answer the research questions, a literature review was conducted with the goal to understand what is behind CFs' challenges and the motivations to become part of a CF. The results showed that a lack of trust is one of the main reasons why CFs are not commercialized, whereas the motivation could be explained with the resource dependent theory and the resource-based view. Besides, we consider that KM could influence CFs according to the knowledge-based theory. The contribution of this paper is a proposal for a KM Framework for CFs, in order to strengthen stability of the underlying SA by improving trust among the CSPs. Section 2 gives the background on CFs and its challenges that prevent it from being commercialized. Section 3 explains how a $\mathrm{CF}$ can be viewed as a SA, and how this can explain instability of CFs. Based on this, the requirements for applying the concept of $\mathrm{KM}$ to $\mathrm{CF}$ as a SA are defined. Section 4 contains the proposed framework for KM in CFs. In Sect. 5, the article is wrapped up with a discussion and ideas on how to evaluate the model in the future. Lastly, Sect. 6 presents the conclusion.

\section{Background}

$\mathrm{CF}$ is a group of CSPs working together to overcome scalability problems, which are of concern in the cloud computing area [10]. Basically, CSPs collaborate to form a single large CF without merging or changing the individual CSPs functionalities and strategies. The difference is that, whereas a standalone CSP might have trouble meeting users' needs, a CSP in a CF can use available resources of its partners, to meet its customers' demands [11]. Another benefit from CFs is that it allows for smaller CSPs to compete with larger ones [12]. CSPs such as Amazon and Microsoft already control over $50 \%$ of the cloud computing market [13]. Nevertheless, despite the benefits CF brings, it has been difficult to commercialize CFs [14], particularly because of the following issues and challenges. Resource Provisioning: A CF requires to integrate various CSPs with heterogeneous infrastructures. Dynamic service delivery also raises an issue on the efficient resource provisioning techniques for a CF [15]. Resource Management: Reliable and flexible management of SLA in CF is needed, to deliver efficient and flexible services [11]. Security: There is a need for solid user identity management [16], security protocols, authentication, and authorization [16]. Data Management: CFs have to provide data transfer protocols between CSPs and must guarantee long-term 
storing and interoperable sharing among CSPs [17]. Trust and Confidence: boosting trust and confidence between CSPs are important towards the implementation $[1,17]$ and commercialization of CF [10].

\section{Requirements for Knowledge Management in Cloud Federations}

This section describes three requirements for applying the proposed KM framework to CFs: (1) identifying and defining common strategic objectives among CSPs, (2) identifying the nature of knowledge to be shared, and (3) protecting the knowledge to be shared.

\subsection{Cloud Federation as a Strategic Alliance}

Prior research supports the idea of representing a CF as a SA [18]. A CF is a projection of SA, specifically, a joint venture between CSPs. The latter is similar to CF establishments, because both embed signed agreements to join and work in alliance.

Table 1. Mapping motives for CF creation and alliance formation (based on [19]).

\begin{tabular}{l|l|l}
\hline Underlying theory & Specific motive & Seminal authors \\
\hline Resource Dependency Theory & $\begin{array}{l}\text { Lack of Self-sufficiency Leads to } \\
\text { Dependence, Vertical Links }\end{array}$ & $\begin{array}{l}\text { Pfeffer and Salancik } \\
\text { (1978), Pfeffer and } \\
\text { Novak (1976), Glaister } \\
\text { and Buckley (1996) }\end{array}$ \\
\hline Resource Based View (RBV) & $\begin{array}{l}\text { Resource Exchange-Access to } \\
\text { Complementary/Supplementary } \\
\text { Resources }\end{array}$ & $\begin{array}{l}\text { Dan and Teng (2000a), } \\
\text { Tsang (1998) }\end{array}$ \\
\hline Knowledge-Based Theory & Inter-organizational Learning & $\begin{array}{l}\text { Larsson et al. (1998), } \\
\text { Hamed (1991), Gils and } \\
\text { Zwart (2004) }\end{array}$ \\
\hline
\end{tabular}

Moreover, SAs are motivated by some theories such as: comprising resource dependence theory [20], transaction cost economics [21], resource-based view [22], institutional theory [23], and network theory [24]. The motivation to establish a CF can be projected on those cited theories. However, according to the basic definition of CF, it is first linked to the resource dependence theory, followed by the resource-based view (Table 1). It is also proposed to extend existing motivations for a CF creation by utilizing knowledge-based theory. 


\subsection{Strategic Alliance Instability in the Context of Cloud Federations}

Despite the growing trend of SA formations, the rate of failure is high [22]. Resource dependence theory [20] explains one of the motivations for SA formations. Ultimately, the target of this kind of alliance is to control the resource dependence as well as the risk. After firms satisfy their needs, and succeed in acquiring the requested resources, the alliance motivation dies, and the inter-firm relationship may end [22]. In the case of $\mathrm{CFs}$, the residual mutual resource needs of CSPs may play in favor of the stability of the $\mathrm{CF}$ and create a certain immunity against such turbulences.

Soft facts, such as trust, could be crucial to the stability of the SA. Moreover, hard facts, such as strategic compatibility and appropriate governance mechanisms, may strengthen the SA and could have a tangible positive influence on alliance stability [25]. Thus, the lack of trust and the lack strategic compatibility may lead to instability of the SA. In addition to that, at the SA level, Bhattacharya et al. [26] defined four trust-inducing ways: (1) alignment of interests and strategic goals, (2) value alteration, (3) selectivity in transactions, and (4) research and knowledge revelation. Furthermore, theory often emphasizes the importance of sharing knowledge, when it comes to building trust [27]. These findings drive the focus on the relation between knowledge sharing among CSPs and the identification of the common strategic objectives, which are considered the first requirement for constructing our KM framework, aiming at raising the stability of CFs.

\subsection{Strategic Alliances and Knowledge Management in the Context of Cloud Federations}

Previous literature has also examined the impact of $\mathrm{KM}$ on stability and success of SAs [6-8]. Moreover, as CF leverages SAs [5], the relationship between KM, SA, and CFs can be depicted as shown in Fig. 1. In addition to this, both academics and practitioners work on understanding how to develop alliance capabilities, in order to raise the rate of alliance success [6]. In particular, the manner, in which the inter-organizational learning process is managed, has an important role into determining success or failure of the SAs [7].

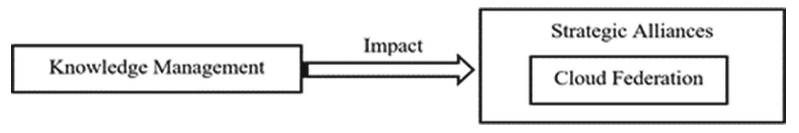

Fig. 1. Impact of knowledge management on the success of CFs as a SAs.

A project named Basmati was designed to strengthen the support of applications and services that run in a $\mathrm{CF}$ environment. It improves the service quality perceived by end users [5,28]. Within this project, knowledge sharing between components has been considered but is limited to resource information. If there were more diversified knowledge sharing between CSPs than only sharing resource information's, the CF may gain further stability and trust among CSPs. 
The knowledge theory [27-29] is considered one of the most important theories that motivates the formation of SAs [19]. In addition, many empirical studies gave evidence that KM (i.e., codifying, sharing, articulating, and internalizing) has a positive relation with the overall stability and success of SAs [6]. SAs face some learning issues, such as non-controlled information revelation, or unbalanced dissemination of core competences between the SA actors $[29,30]$. These issues push to think about the nature of the knowledge to be shared within the CF. Buckley et al. (2009) argued that combining specific knowledge benefits firms when implementing common goals, which cannot be implemented individually [31]. Figure 2 describes this process in a CF environment, in which CSPs identify a common goal $\mathrm{C}$, identify the knowledge to share while keeping individual goals A and B separate. Developing the capability of knowing the nature of the knowledge to be shared within the $\mathrm{CF}$ represents the second requirement to build the KM framework for CFs.

\begin{tabular}{|c|c|c|c|c|}
\hline \multirow{2}{*}{$\begin{array}{l}\text { Service provider 1: } \\
\text { Strategic Goal A }\end{array}$} & $\begin{array}{l}\text { Shared Knowledge } \\
\text { In line with Goal C }\end{array}$ & \multirow{2}{*}{$\begin{array}{c}\text { Shared Strategic Goal C } \\
\text { Knowledge cocreation }\end{array}$} & $\begin{array}{l}\text { Shared Knowledge } \\
\text { In line with Goal C }\end{array}$ & \multirow{2}{*}{$\begin{array}{l}\text { Service provider 2: } \\
\text { Strategic Goal B }\end{array}$} \\
\hline & New Knowledge & & New Knowledge & \\
\hline
\end{tabular}

Fig. 2. Relation between the nature of the shared knowledge and the strategic objectives within CFs (adapted from [31]).

\subsection{Strategic Alliances and Knowledge Protection in the Context of Cloud Federations}

Most studies claim to share and protect knowledge, yet, at the same time, reveal certain incompatibilities of knowledge sharing and protecting [32]. However, few studies argue that sharing and protecting knowledge is crucial to the overall success of SAs [33]. Guo et al. [34] demonstrate the existence of a complementarity between applying knowledge sharing and knowledge protection simultaneously, in addition to the positive effect of this ambidexterity on SAs [34]. Therefore, the protection of knowledge to be shared among CSPs has a positive impact on the stability of CFs. Based on this finding, the third requirement is the protection of the knowledge to be shared.

\section{Knowledge Management Framework}

Based on the requirements and the literature review aforementioned, various KM frameworks were examined. Among them, the Inter-Organizational System (IOS) addresses trust and KM relationships, as well as their impact on stability of alliances [9]. Thus, the proposed KM model for CFs is an extension of the IOS collaboration model, with respect to following requirements: (1) identifying the common strategic objectives among CSPs, (2) identifying the nature of the knowledge to be shared, in line with the defined common strategic objectives, and (3) selecting the methods of knowledge protection based on its nature and existing commitment between a $\mathrm{CF}$ and the participating CSPs. 
The proposed framework aims to raise trust and commitment among the participants, and it also encourages knowledge sharing among CSPs to strengthen the SA [9, 34, 35]. The adopted and extended model (Fig. 3) presents the relation between KM, trust, and commitment within an IT and communication infrastructure. This choice helps building on existing software modules used by $\mathrm{CFs}$, dedicated exclusively to managing the information related to resource management (prediction, planning, and allocation). As argued by [9], the relation between KM and trust-commitment is bidirectional. Therefore, it can be stated that the more CSPs trust each other, the more they share knowledge and cooperate, and that the more CSPs share knowledge, the more they create added value and trust each other.

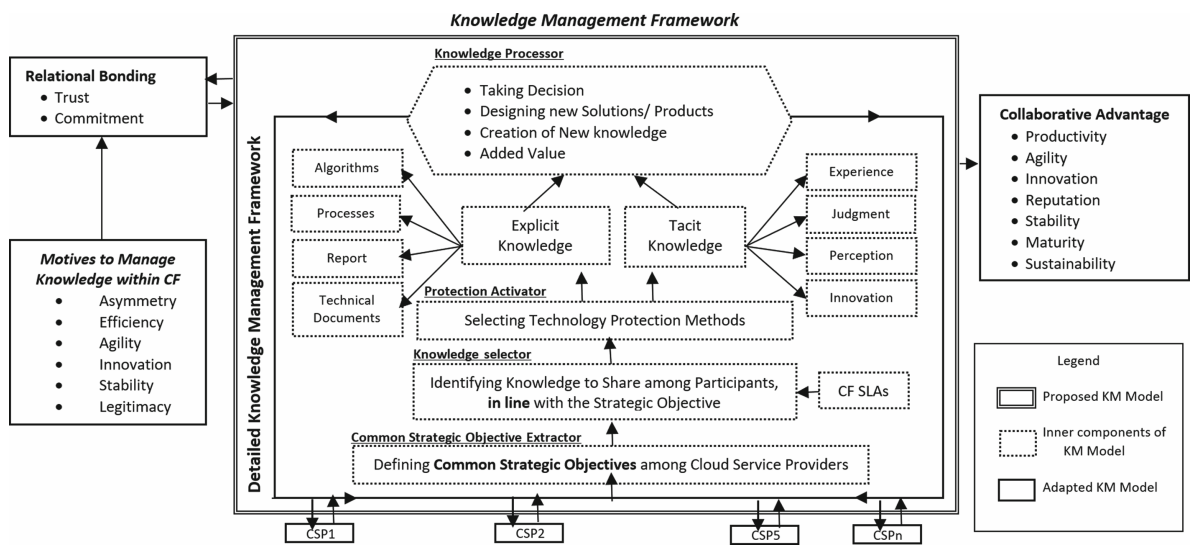

Fig. 3. Knowledge management framework for CF (adapted from [9] [31]).

In the proposed framework (Fig. 3), the starting point is to identify CSPs common strategic objectives, through the "Common Strategic Objectives Extractor". It also represents the foundation of a relation built on trust, transparency, and guarantees that all the members pursue the same goals. Some common objectives may change by the dynamic environment, or by individual CSPs' goals. Then, the "Knowledge Selector" component enables CSPs to identify the nature of the knowledge to be shared, in line with common strategic goals and service level agreements between federation members. In the next stage, the "Protection Activator" enables CSPs to select an appropriate protection mechanism depending on the nature of the knowledge. This knowledge could be tacit (i.e., knowledge based on experience, perception, judgement) or explicit (i.e., knowledge based on data, algorithms, technical documents). Once the knowledge to be shared is identified, and its protection method has been defined, the knowledge is shared, and directed to the fourth component, "Knowledge Processor". Within this component, new knowledge is created, and new solutions or products are designed. The output induces to several collaborative advantages, namely agility, productivity, reputation, and, most importantly, the stability of the CF. The final knowledge output goes back to the CSPs and CF, while also raising commitment and trust among the CSPs. 


\section{Discussion and Future Work}

The paper proposes a $\mathrm{KM}$ framework for CFs to increase stability and potential $\mathrm{CF}$ commercialization. For the methodology, a literature review was conducted to understand CFs' challenges and motivations. The results showed that a lack of trust is one of the main reasons why $\mathrm{CFs}$ are not commercialized whereas the motivations were the resource dependent theory and the resource-based view. Besides, it is argued that KM influences CFs based on the knowledge-based theory.

To clarify the whole process of KM framework, consider a couple of CSPs collaborating in a CF. Although every CSP faces a myriad of cyber-attacks, the security mechanism of each CSP varies from each other due to the difference in their security infrastructure [36, 37]. This kind information, like security mechanism or attack patterns, is too sensitive to share with any third party [38]. However, within a CF, there is trust, which makes the sharing of such information possible. By using the proposed KM framework, each CSP shares their cyber threat information with each other, allowing them to develop a strong security method. This can be granted as a common strategic objective. By sharing their explicit knowledge (e.g., necessary cyber threat information and protection technology) and tacit knowledge (e.g., expertise and skill) a new stronger security technique can emerge and be used by all CF members.

The framework limitation is the evaluation stage. Thus, it opens a window to research about evaluation and test methods. The empirical evidence through tests can be split in two categories: 1) Analysis of existing case studies of KM in SAs and comparing the KM dynamics with the present proposal. Similarities and differences with respect to success or failure of the selected SA will bring further insight towards the validity of the proposed framework; 2) Perform surveys or interviews with experts in the CF field.

\section{Conclusion}

This article addressed the trust between cloud service providers (CSPs) in cloud federations (CFs), for its importance in keeping CSPs in CFs. It also analyzed the impact of knowledge management (KM) on CF stability from a strategic alliance (SA) perspective. Based on an extensive SA literature review, a KM framework was proposed and discussed.

Acknowledgment. This research was supported by the BK21 FOUR (Fostering Outstanding Universities for Research) funded by the Ministry of Education (MOE, Korea) and National Research Foundation of Korea (NRF). This work was also supported by the National Research Foundation of Korea (NRF) grant (No. NRF-2019R1F1A1058487) funded by the Ministry of Science and ICT (MSIT) of Korea. 


\section{References}

1. Kanwal, A., Masood, R., Shibli, M.A.: Evaluation and establishment of trust in cloud federation (2014). https://doi.org/10.1145/2557977.2558023

2. Jones, S., Irani, Z., Sivarajah, U., Love, P.E.D.: Risks and rewards of cloud computing in the UK public sector: a reflection on three organisational case studies. Inf. Syst. Front. 21(2), 359-382 (2017). https://doi.org/10.1007/s10796-017-9756-0

3. Romero Coronado, J.P., Altmann, J.: Model for incentivizing cloud service federation. In: Pham, C., Altmann, J., Bañares, J.Á. (eds.) GECON 2017. LNCS, vol. 10537, pp. 233-246. Springer, Cham (2017). https://doi.org/10.1007/978-3-319-68066-8_18

4. Nguyen, P.D., Thoai, N.: DrbCF: a differentiated ratio-based approach to job scheduling in cloud federation. In: Proceedings - 2016 10th International Conference Complex, Intelligent, Software Intensive Syststem. CISIS 2016, pp. 31-37 (2016). https://doi.org/10.1109/CISIS. 2016.93

5. Altmann, J., et al.: BASMATI: an architecture for managing cloud and edge resources for mobile users. In: Pham, C., Altmann, J., Bañares, J.Á. (eds.) GECON 2017. LNCS, vol. 10537, pp. 56-66. Springer, Cham (2017). https://doi.org/10.1007/978-3-319-68066-8_5

6. Kale, P., Singh, H.: Building firm capabilities through learning: the role of the alliance learning process in alliance capability and firm-level alliance success. Strateg. Manag. J. 28(10), 9811000 (2007). https://doi.org/10.1002/smj.616

7. Larsson, R., Bengtsson, L., Henriksson, K., Sparks, J.: The interorganizational learning dilemma: collective knowledge development in strategic alliances. Organ. Sci. 9(3), 285-305 (1998). https://doi.org/10.1287/orsc.9.3.285

8. Meier, M.: Knowledge management in strategic alliances: a review of empirical evidence. Int. J. Manag. Rev. 13(1), 1-23 (2011). https://doi.org/10.1111/j.1468-2370.2010.00287.x

9. Chi, L., Holsapple, C.W.: Understanding computer-mediated interorganizational collaboration: a model and framework. J. Knowl. Manag. 9(1), 53-75 (2005). https://doi.org/10.1108/ 13673270510582965

10. Aryal, R.G., Altmann, J.: Dynamic application deployment in federations of clouds and edge resources using a multiobjective optimization AI algorithm. In: 2018 3rd International Configuration Fog Mobile Edge Computing. FMEC 2018, pp. 147-154 (2018). https://doi. org/10.1109/FMEC.2018.8364057

11. Aryal, R.G., Altmann, J.: Fairness in revenue sharing for stable cloud federations. In: Pham, C., Altmann, J., Bañares, J.Á. (eds.) GECON 2017. LNCS, vol. 10537, pp. 219-232. Springer, Cham (2017). https://doi.org/10.1007/978-3-319-68066-8_17

12. Aryal, R.G., Marshall, J., Altmann, J.: Architecture and business logic specification for dynamic cloud federations. In: Djemame, K., Altmann, J., Bañares, J.Á., Agmon Ben-Yehuda, O., Naldi, M. (eds.) GECON 2019. LNCS, vol. 11819, pp. 83-96. Springer, Cham (2019). https://doi.org/10.1007/978-3-030-36027-6_8

13. Stalcup, K.: AWS vs Azure vs Google Cloud Market Share 2021: What the Latest Data Shows - ParkMyCloud. ParkMyCloud (2021). https://www.parkmycloud.com/blog/aws-vsazure-vs-google-cloud-market-share/. Accessed 19 June 2021

14. L. Code: Economic Models for Incentivizing the Federations of IaaS Cloud Providers (2021)

15. Rajarajeswari, C.S.: Challenges in Federated Cloud, vol. 4, pp. 2394-2697 (2017)

16. Villari, M., Brandic, I., Tusa, F.: Achieving federated and self-manageable cloud infrastructures: Theory and practice. IGI Global (2012)

17. Ahmed, U., Raza, I., Hussain, S.A.: Trust evaluation in cross-cloud federation: survey and requirement analysis. ACM Comput. Surv. 52(1), 1-37 (2019). https://doi.org/10.1145/329 2499 
18. Haile, N., Korea, S.: College of Engineering Technology Management, Economics, and Policy Discussion Paper Series Risk-Benefit-Mediated Impact of Determinants on the Adoption of Cloud Federation, January 2015

19. Dhaundiyal, M., Coughlan, J.: Understanding strategic alliance life cycle: a 30 year literature review of leading management journals. Bus. Theory Pract. 21(2), 519-530 (2020). https:// doi.org/10.3846/btp.2020.11530

20. Reitz, H.J., Pfeffer, J., Salancik, G.R.: The external control of organizations: a resource dependence perspective (New York: Harper \& Row, 1978). Acad. Manag. Rev. 4(2), 309-310 (1979)

21. Kogut, B.: Joint ventures: theoretical and empirical perspectives. Strateg. Manag. J. 9(4), 319-332 (1988). https://doi.org/10.1002/smj.4250090403

22. Das, T.K., Teng, B.S.: Instabilities of strategic alliances: an internal tensions perspective. Organ. Sci. 11(1), 77-101 (2000). https://doi.org/10.1287/orsc.11.1.77.12570

23. Tina Dacin, M., Oliver, C., Roy, J.P.: The legitimacy of strategic alliances: an institutional perspective. Strateg. Manag. J. 28(2), 169-187 (2007). https://doi.org/10.1002/smj.577

24. Gulati, R.: Alliances and networks. Strateg. Manag. J. 19(4), 293-317 (1998). https://doi.org/ 10.1002/(SICI)1097-0266(199804)19:4\%3c293::AID-SMJ982\%3e3.0.CO;2-M

25. Hoffmann, W.H., Schlosser, R.: Success factors of strategic alliances in small and medium -sized enterprises - An empirical survey. Long Range Plan. 34(3), 357-381 (2001). https:// doi.org/10.1016/S0024-6301(01)00041-3

26. Bhattacharya, R., Devinney, T.M., Pillutla, M.M.: A formal model of trust based on outcomes. Acad. Manag. Rev. 23(3), 459 (1998). https://doi.org/10.2307/259289

27. Das, T.K., Teng, B.S.: Trust, control, and risk in strategic alliances: an integrated framework. Organ. Stud. 22(2), 251-283 (2001). https://doi.org/10.1177/0170840601222004

28. Kim, S.: HORIZON2020 FRAMEWORK PROGRAMME TOPIC EUK-03-2016 Federated Cloud resource brokerage for mobile cloud services (2016)

29. Hamel, G.: Competition for competence and inter- partner learning within international. Strateg. Manag. J. 12, 83-103 (1991)

30. Bresser, R.K.F.: Matching collective and competitive strategies. Strateg. Manag. J. 9(4), 375385 (1988). https://doi.org/10.1002/smj.4250090407

31. Buckley, P.J., Glaister, K.W., Klijn, E., Tan, H.: Knowledge accession and knowledge acquisition in strategic alliances: the impact of supplementary and complementary dimensions. Br. J. Manag. 20(4), 598-609 (2009). https://doi.org/10.1111/j.1467-8551.2008.00607.x

32. Yang, S.M., Fang, S.C., Fang, S.R., Chou, C.H.: Knowledge exchange and knowledge protection in interorganizational learning: the ambidexterity perspective. Ind. Mark. Manag. 43(2), 346-358 (2014). https://doi.org/10.1016/j.indmarman.2013.11.007

33. Wu, F., Sinkovics, R.R., Cavusgil, S.T., Roath, A.S.: Overcoming export manufacturers' dilemma in international expansion. J. Int. Bus. Stud. 38(2), 283-302 (2007). https://doi.org/ 10.1057/palgrave.jibs. 8400263

34. Guo, W., Yang, J., Li, D., Lyu, C.: Knowledge sharing and knowledge protection in strategic alliances: the effects of trust and formal contracts. Technol. Anal. Strateg. Manag. 32(11), 1366-1378 (2020). https://doi.org/10.1080/09537325.2020.1769840

35. Castelfranchi, C.: Trust mediation in knowledge management and sharing. In: Jensen, C., Poslad, S., Dimitrakos, T. (eds.) iTrust 2004. LNCS, vol. 2995, pp. 304-318. Springer, Heidelberg (2004). https://doi.org/10.1007/978-3-540-24747-0_23

36. Rashid, Z., Noor, U., Altmann, J.: Economic model for evaluating the value creation through information sharing within the cybersecurity information sharing ecosystem. Futur. Gener. Comput. Syst. 124, 436-466 (2021). https://doi.org/10.1016/J.FUTURE.2021.05.033 
37. Rashid, Z., Noor, U., Altmann, J.: Network externalities in cybersecurity information sharing ecosystems. In: Coppola, M., Carlini, E., D’Agostino, D., Altmann, J., Bañares, J.Á. (eds.) GECON 2018. LNCS, vol. 11113, pp. 116-125. Springer, Cham (2019). https://doi.org/10. 1007/978-3-030-13342-9_10

38. Noor, U., Anwar, Z., Altmann, J., Rashid, Z.: Customer-oriented ranking of cyber threat intelligence service providers. Electron. Commer. Res. Appl. 41, 100976 (2020). https://doi. org/10.1016/j.elerap.2020.100976

Open Access This chapter is licensed under the terms of the Creative Commons Attribution 4.0 International License (http://creativecommons.org/licenses/by/4.0/), which permits use, sharing, adaptation, distribution and reproduction in any medium or format, as long as you give appropriate credit to the original author(s) and the source, provide a link to the Creative Commons license and indicate if changes were made.

The images or other third party material in this chapter are included in the chapter's Creative Commons license, unless indicated otherwise in a credit line to the material. If material is not included in the chapter's Creative Commons license and your intended use is not permitted by statutory regulation or exceeds the permitted use, you will need to obtain permission directly from the copyright holder.

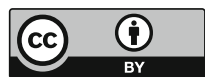

